\title{
MAIN TRENDS IN ORGANIZING THE ATTACK OF THE BRAZILIAN NATIONAL VOLLEYBALL TEAM ON MEN'S WORLD CHAMPIONSHIP POLAND2014
}

\author{
Vladimir Kotev \\ NSA"Vassil Levski"
}

\begin{abstract}
Summary
Typical trend for modern volleyball is the big variety of combination of both individual and collective techno-tactical actions. The potential and level of a team are directly related to the potential and level of the setter. The aim of the study is to analyze the main sides of Bruno Rezende's play in organizing the Brazilian attack on the Men's World Volleyball Championship in Poland 2014. The subject of the study is the competitive process for elite volleyball teams. The subject of the study are the specific for the setter parameters and game parameters that determine his efficiency. The game efficiency analysis has been realized with the modern software "Data Volley", using an alternative and graphical analysis of the results. Having all options in attack available, the Brazilian attack is very variable and unpredictable. As a trend in Bruno Rezende's game, is the frequent use of the middle attackers. When organizing the counterattack of his team, he stays unpredictable in cases when 1st tempo attack is available. In the other cases, the Brazilian setter prefers to set the balls for attack in zone 4.
\end{abstract}

Key words: volleyball, the team of Brazil, World championship, setter, organizing the attack

\section{Introduction}

Certainly with the development of the volleyball game, the requirements for all players, and especially for the one charged with the organizational functions on the court, the setter, are also increasing. Just setting the ball to the attackers is not enough to reach high sporting-technical level (Ivanov N., Kotev V., 2016)

Game analysis plays an important role in the development of several collective sports modalities, presenting itself as a determinant factor in the choice of pertinent indicators regarding players' performance in specific contexts (Mesquita I.,1996). It also aims to prepare the team for confrontation with the opponent, improve the quality of training and analyze the game structure (Lames M., Hansen G., 2011).

Game analysis in Volleyball, regarding the effects of procedures that constitute it (serve, reception, set, attack, block and defense), is not recent. The game is characterized by two complexes: complex I (KI) or side-out, consisting of the sequence of actions formed by the reception, setting and attacking, and Complex II (KII) or transition, the sequence of actions formed by the serve, block, defense and counterattack (Stutzig N. et al., 2015)
Analysis of the playing activity of the setters allows to see the tactical concept of the team in attack. Thinking in volleyball is a psychological process of searching and revealing the connections and interactions between the components creating the volleyball activity and the actual conditions of its implementation (Bozhilov, G., 2003). Each setter has to carefully assess each situation and make the most appropriate decision for scoring a point. He must be able to analyze in a short time which attacker is in best position to score a point and which of the attackers can put $100 \%$ of his ability to outplay the ball.

The high quality receptions led to attack strategies using the attackers in the attack zone, that is, in positions 2,3 and 4, probably due to the greater probability of scoring, since these athletes were closer to the net (Costa, G. et al., 2016; Marcelino et al., 2014, Millán-Sanchez et al., 2015). The most used tempo was the 2nd, followed by the 3rd and the 1st tempo (Panfil R., Superlak E., 2012). Men's teams are increasingly seeking to perform a faster game in order to overlap the opposing defense system. In addition, it can also be said that the type of game practiced in Brazil has different characteristics from the game played in other countries (Costa, G. et al., 2016; Silva M., Lacerda D., João P., 2014). 
The present study will allow us to trace the main features of organizing the attack of one of the most successful national teams in the world - the Brazilian mens team, and will answer the question: „Why does this team win medals and titles from any championship that participates?"

\section{Aim and Objectives of the study}

The aim of the study is to analyze the main features of Bruno Rezende's play in organizing the Brazilian attack on the World Volleyball Championship for Men in Poland in 2014. The subject of the study is the competitive process for elite volleyball teams. The subject of the study are the specific for the setter parameters and game parameters that determine his efficiency. Contingent of study are a total of 698 game actions of the setter - 487 in organizing 1st tempo attack and 211 in organizing the counterattack of the Brazilian national team.

\section{Methods}

The game efficiency analysis has been made with the modern software „Data Volley", using an alternative and graphical analysis of the results. The game activities of the setters were recorded in the organization of the attack after receiving (in the case of a side out) and after a successful defense game (counterattack) in a technical-tactical aspect. In the tactical direction of analyzing the efficiency of the setter's play, the following indicators were examined:

- General distribution of the setter

- Distribution of the setter after excellent reception (\#)

- Distribution of the setter after positive reception (+)

- Distribution of the setter after negative reception (!)

- Distribution of the setter on counter-attack after defense

- Distribution of the setter on counterattack after free ball

At present, $95 \%$ of national and club teams use the "Data Volley" video-statistical analysis system. The use of this analysis system provides valuable information about the actions of the setter during the game:

$\checkmark \quad$ Whom he prefers setting the ball to;

$\checkmark$ how he organizes the attack after reception away from the net;

$\checkmark$ how much skills he has to pass behind his head

$\checkmark$ Does he move quickly when coming from back court;

\section{Watches the opponent block}

The system of attack organization depends very much on reception the service. In today's volleyball, several grades have been highlighted for the quality of the reception. All leading teams use this rating system.

1. Excellent reception (\#) the ball is passed next to the net in the middle of the court (Figure 1). Between the setter and the net no other player can stand. The setter is not moved to zone 2 or zone 4 . Perfect position for organizing variation attack. So passed ball gives the setter possibility to include all the players in different combinations. Allows first tempo attack to be used, where the attacker always has the advantage over the blocker in speed and knows where the ball will be passed from the setter.

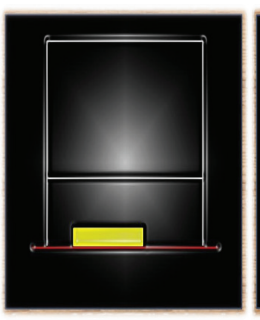

Figure 1

Excellent reception (yellow zone)

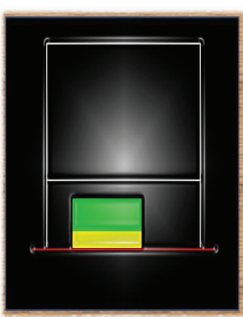

Figure 2

Positive reception (green zone)

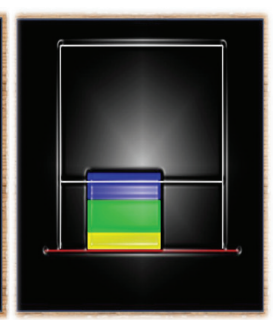

Figure 3

Negative reception (blue zone)
2. Positive reception $(+)$ - the ball is passed close to the net, but $1,5-2 \mathrm{~m}$ from it. Between the setter and the net, other player can stand (Figure 2). The first tempo attacker's jump is changed.

3. Negative reception (!) - the ball is passed around the attack line. First tempo attack is impossible to be played (Figure 3). This type of reception significantly reduces the possibilities for combinative play. The options of the setter for outplaying organized opponent's triple block are fast ball for outside hitters or attack from zone six (Pipe).

\section{${ }^{\star}$ Used volleyball terminology:}

$\checkmark$ Distribution - the balls passed to the attackers

$\checkmark$ First tempo - fast speed attack close to the setter with the middle attacker

$\checkmark$ Calling - specifying variation of interaction between the setter and the first tempo attacker 
Pipe - combination in attack, where the ball is passed for attack to a player from back court, located in zone 6

\section{Results}

The results obtained after the statistical processing of the data shows that the Brazilians prefer speed in organizing the attack. Bruno Rezende has a great variety. Unlike other setters who use callings to the central attackers only to mislead the opponent block, and in order to stretch the front of the attack, he cleverly and rationally uses his middle attackers. Many of the points are made after organizing an attack at the center of the net. From the data shown in Table 1, it can be seen that the total number of balls passed to the middle attackers is 147 , of which 100 points were scored and only 7 errors were made. The effectiveness of the center attack is $68 \%$, which is extremely high, against the backdrop of equal opportunities for competitors and strong competition in modern volleyball. An impression makes Saatkamps heavy workload, to who 92 balls for attack were distributed from a total of 487 first tempo attacks. This seems completely logical, as he shows extremely high effectiveness of side out attack $-72 \%$.

Table 1 The effectiveness of the Brazilian team in playing first tempo

\begin{tabular}{|c|c|c|c|c|c|c|c|c|c|c|c|c|c|c|c|}
\hline Skill & Type & Player & Tot & $=$ & $\%$ & l & $\%$ & - & $\%$ & $!$ & $\%$ & + & $\%$ & \# & $\%$ \\
\hline \multirow[t]{2}{*}{ Attack after reception } & $\begin{array}{l}\text { First } \\
\text { tempo }\end{array}$ & Team & 147 & 7 & $5 \%$ & 6 & $4 \%$ & 22 & $15 \%$ & 8 & $5 \%$ & 4 & $3 \%$ & 100 & $68 \%$ \\
\hline & & Saatkamp & 92 & 3 & $3 \%$ & 4 & $4 \%$ & 10 & $11 \%$ & 5 & $5 \%$ & 4 & $4 \%$ & 66 & $72 \%$ \\
\hline
\end{tabular}

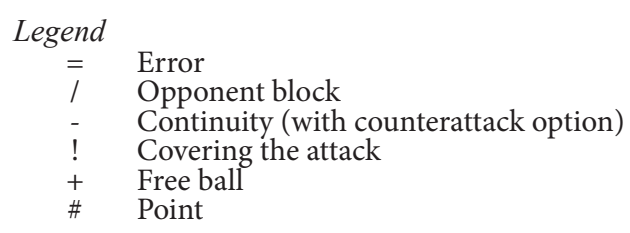

In the different positions of the setter on the court (Figure 4) there are several features, which depends on the first tempo calling:

Well-balanced balls distribution of the balls to the attackers and predominant play with middle attackers - between $35 \%$ and $40 \%$ gameplay in the center of the net;

When setter is in zone 6, the first option for distribution is zone $4-42 \%$ of the balls are passed there. However, most of them is when the middle attacker is called to play ball behind the setter's head. At $62 \%$ on such approach in the center, the Brazilian setter prefers to turn the attack front and to pass the ball to the outside hitter in zone 4 .
In the same position, Bruno's preference for high speed ball in the center is also noticeable, with $56 \%$ of the time playing with the central attacker.

When in zone 3 he also often targets the attack to the middle attackers, again playing $47 \%$ with a fast ball in. It is noticeable that in this position Bruno Rezende did not use the gameplay with the central behind the head.

In zone 1 is noticeable preferable play on first tempo $-41 \%$ of all balls in attack. Also, the attack often is targeted to the center behind setter's head. In this position the Brazilian setter did not use high-speed ball in the center. 
Fig.4 Bruno Rezende distribution in zones

\begin{tabular}{|c|c|c|c|c|c|c|c|c|c|c|c|c|}
\hline \multicolumn{3}{|c|}{ Back calling } & \multicolumn{3}{|c|}{ Low ball calling } & \multicolumn{3}{|c|}{$\begin{array}{l}\text { High-speed ball } \\
\text { calling }\end{array}$} & \multicolumn{3}{|c|}{ Total } & \\
\hline 2 & \multicolumn{2}{|l|}{34} & 1 & \multicolumn{2}{|l|}{34} & 7 & \multicolumn{2}{|l|}{1} & TOT & \multicolumn{2}{|l|}{85} & \\
\hline . & & & . & & & . & & & . & & & \\
\hline . & & & 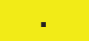 & & & . & & & . & & & \\
\hline & $15 \%$ & & & $18 \%$ & & & . & & & $14 \%$ & & \\
\hline & 5 & & & 6 & & & . & & & 12 & & P1 \\
\hline $18 \%$ & $35 \%$ & $32 \%$ & $15 \%$ & $41 \%$ & $26 \%$ & . & . & $100 \%$ & $15 \%$ & $40 \%$ & $31 \%$ & \\
\hline 6 & 12 & 11 & 5 & 14 & 9 & . & . & 1 & 13 & 34 & 26 & \\
\hline 2 & 29 & & 1 & 23 & & 7 & 9 & & TOT & 71 & & \\
\hline$\cdot$ & & & $\cdot$ & & & $\cdot$ & & & - & & & \\
\hline . & $7 \%$ & & . & 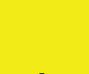 & & - & 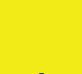 & & . & $4 \%$ & & \\
\hline & 2 & & & . & & & 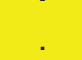 & & & 3 & & P6 \\
\hline $10 \%$ & $21 \%$ & $62 \%$ & $39 \%$ & $43 \%$ & $17 \%$ & $22 \%$ & $56 \%$ & $22 \%$ & $20 \%$ & $34 \%$ & $42 \%$ & \\
\hline 3 & 6 & 18 & 9 & 10 & 4 & 2 & 5 & 2 & 14 & 24 & 30 & \\
\hline 2 & 1 & & 1 & 28 & & 7 & 17 & & TOT & 55 & & \\
\hline$\cdot$ & & & $14 \%$ & & & $0 \%$ & & & $9 \%$ & & & \\
\hline . & & & 4 & & & 0 & & & 5 & & & \\
\hline & . & & & $21 \%$ & & & $12 \%$ & & & $15 \%$ & & \\
\hline & . & & & 6 & & & 2 & & & 8 & & P3 \\
\hline . & . & $100 \%$ & $36 \%$ & $25 \%$ & $4 \%$ & $24 \%$ & $47 \%$ & $18 \%$ & $31 \%$ & $31 \%$ & $15 \%$ & \\
\hline . & . & 1 & 10 & 7 & 1 & 4 & 8 & 3 & 17 & 17 & 8 & \\
\hline
\end{tabular}

These data show that Bruno Rezende feels comfort- Fig.5 Bruno Rezende distribution after excellent and posiable when playing a fast and cobinative game. It is tive reception, setter in zone 6 also noteworthy the good synchronicity between the attackers and the setter.

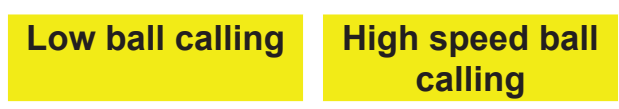

Setter distribution on excellent and positive reception

These are the situations when the ball is passed close to the net and allows the setter to trigger all of its attackers in attack or when a ball is within 1.5 meters of the net. Such balls are a problem for some setters to play first tempo with, but not for Bruno Rezende. The general plan shows that he has no problem playing with the central attackers when the ball is 1.5 meters from the net. Analysis of the results of Figure 5 shows that in the cases where the Brazilian setter is in zone 6 , after calling the middle attackers for first tempo low ball, he passes to them at a total of $48 \%$. In the same rotation there is another interesting trend - when called for a fast ball he passes in $50 \%$ of the cases

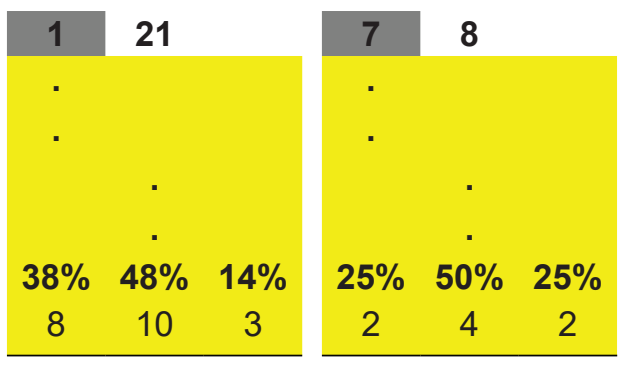

Distribution of the setter after defensive actions and free ball

The results obtained from the statistical processing with the Data-volley program show the affinity of the Brazilian setter for a play on first tempo when there is a precondition for the counter-attack (Figure 6). In a counter-attack in over $30 \%$ of the time 
he plays with his middle attackers. At the same time he skillfully distributes the game along the ends of the net, which further difficult opponent block. Out of a total of 144 digs after which the distributor had a chance to play with first tempo, with $38 \%$ attack is targeted to the central attackers, $26 \%$ to zone 2 and $24 \%$ to zone 4 . When there is no possibility to play with the first tempo in $86 \%$ of the time, the ball was passed to zone 4.

Fig. 6 Bruno Rezende distribution when organizing counterattack

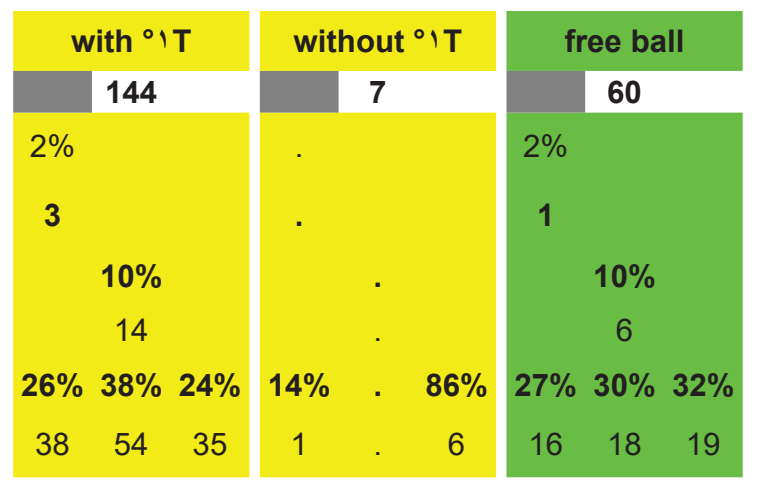

After a free ball, Bruno Rezende very skillfully distributes the attack among all attackers, including a second line from zone 6 (Pipe). Out of a total of 60 balls for the entire championship, $30 \%$ of them he preferred to play in the center, $27 \%$ of the attacks are in zone 2,32\% in zone 4 and 10\% in zone 6.

\section{Discussion}

Bruno has underhand pass technique to perfection, giving him safety and calmness at the court. He has the ability to direct the ball from any position on the court, regardless of the type of movement to it. $\mathrm{He}$ has a look at everything happening on the playing field, both in his team and in the opponent's one. With all the attack options available, the Brazilian attack, skillfully led by Bruno Rezende, is very varied and unpredictable. In many crucial moments, the Brazilian setter takes non-standard solutions, as the analysis shows. In organizing the Brazilian attack, Bruno Rezende's distribution to the attackers is equable which makes organizing opponent's block much more difficult. Main trend in Bruno Rezende's play is the frequent use of the middle blockers in both organizing side out attack and counterattack.

\section{References}

Bozhilov, G. (2003). Takticheski aspekti na motivite $\mathrm{u}$ volejbolistki pri opredelqne resheniqta $\mathrm{v}$ ataka // Божилов, Г. (2003). Тактически аспекти на мотивите у волейболистки при определяне решенията в атака. Спорт и наука, Изв.бр.3, София, 177-182.

Costa, G. et al. (2016), Men's high level volleyball: association berween game actions on the side-out, available at: http://www.scielo.br/scielo.php?pid=S2448-245520160 00100148\&script=sci arttext, (accessed 10 June, 2016).

Ivanov N., Kotev V. (2016). Osnovni tendencii v igrata na razpredelitelq na bulgarskiq nacionalen otbor po volejbol pri organizirane na napadenieto. // Иванов, Н., Котев, В. (2016). Основни тенденции в играта на разпределителя на българския национален отбор по волейбол при организиране на нападението. Спорт и наука, 6p.5-6, 61-70.

Lames M., Hansen G (2011), Designing observational systems to support top-level teams in game sports. International Journal Perform Anal Sport 2011; 1(1), pp. 83-90.

Marcelino et al. (2014), Determinants of attack players in high-level men's volleyball. Kinesiology; 46(2) pp. 234-241.

Mesquita I., (1996), Estudo descritivo e comparativo das respostas motoras de jovens voleibolistas de diferentes níveis de desempenho nas situações de treino e competição., Estudos CEJD, Portugal: FCDEF-UP; pp. 32-56.

Millán-Sanchez et al. (2015). Participation in terminal actions according to the role of the player and his location on the court in top-level men's volleyball. International Journal Anal Sport; 15 pp. 608-619.

Panfil R., Superlak E. (2012), The relationships between the effectiveness of team play and the sporting level of a team. Human Movement; 13(2); pp 152-160.

Silva M., Lacerda D., João P. (2014), Game-related volleyball skills that influence victory. J Human Kinetic; 41; pp 173-179.

Stutzig N. et al. (2015), Analysis of game variables to predict scoring and performance levels in elite men's volleyball. International Journal Perform Anal Sport; 15(3), pp. 816-829. 